\title{
Bone marrow mesenchymal stem cells ameliorate rat acute renal failure by differentiation into renal tubular epithelial-like cells
}

\author{
HUI QIAN ${ }^{1 *}$, HUAN YANG $^{1 *}$, WENRONG XU ${ }^{1,2}$, YONGMIN YAN $^{1}$, QIAOLIN CHEN $^{1}$, WEI ZHU ${ }^{1}$, \\ HUILING CAO $^{1}$, QIN YIN $^{2}$, HONGXING ZHOU $^{1}$, FEI MAO $^{1}$ and YONGCHANG CHEN ${ }^{1}$ \\ ${ }^{1}$ Zhenjiang Key Institute of Clinical Laboratory Medicine, School of Medical Technology, Jiangsu University, \\ Zhenjiang 212013; ${ }^{2}$ Department of Clinical Laboratory Medicine, The Affiliated Hospital of \\ Jiangsu University, Zhenjiang 212001, P.R. China
}

Received April 29, 2008; Accepted June 12, 2008

DOI: 10.3892/ijmm_00000026

\begin{abstract}
In the present study, we investigated the therapeutic potential of mesenchymal stem cells (MSCs) in a rat acute renal failure (ARF) model and explored the possible in vivo and in vitro mechanisms of action. Rat and human MSCs were isolated from bone marrow. After being co-cultured with injured kidney tissues in trans-well dishes in vitro, the rat MSCs became rounded renal tubular epithelial-like cells, and highly expressed renal markers such as cytokeratin 18 (CK18) and aquaporin-1 (AQP1). Human MSCs were infused into rats with ARF, and techniques of microscopy, histology, PCR, RT-PCR and fluorescence in situ hybridization were used to characterize the MSCs after transplantation. We found that there were more exogenous human MSCs localized to injured kidney tissues. The kidney recovery rate in the transplanted MSC group was higher than in the control group. Genes associated with human renal tubular epithelial cells such as AQP1 and parathyroid hormone receptor 1 were detected. These findings suggest that the injured kidney tissue induced rat and human MSCs to differentiate into renal tubular epithelial-like cells in vitro and in vivo, and exogenous human MSCs can home specifically to injured regions and efficiently cure rat ARF. These results demonstrate that cell therapy has potential as a novel intervention in ARF.
\end{abstract}

\section{Introduction}

In recent years, much attention has been focused on the plasticity of bone marrow-derived mesenchymal stem cells

Correspondence to: Dr Wenrong Xu, School of Medical Technology, Jiangsu University, 301 Xuefu Road, Zhenjiang 212013, Jiangsu, P.R. China

E-mail: icls@ujs.edu.cn

${ }^{*}$ Contributed equally

Key words: mesenchymal stem cells, acute renal failure, differentiation, kidney
(BM-MSCs). BM-MSCs possess the potential for multidirectional differentiation. They can differentiate, not only into cells homologous with mesodermal interstitial tissue, but also into other cell types (1), such as cardiomyocytes (2), osteoblasts (3), chondrocytes (4), neurocytes (5) and adipocytes (6). Due to the plasticity of MSCs, 'stem cell therapy' offers a therapeutic tool for damaged tissue replacement and tissue engineering. Moreover, MSCs have advantages over conventional stem cells, such as their ease of harvest, stable genetic background, lower risk of tumor formation, and decreased ethical concerns. MSC administration has been shown to be beneficial for healing cardiac tissue following infarction (7), for repairing injured skeletal muscle (8), and for improving the outcome following traumatic brain injury (9).

Acute renal failure (ARF) remains a common and largely treatment-resistant clinical problem with unacceptably high mortality rates, mainly due to the ineffectiveness of currently available therapies. MSCs are an attractive candidate for renal repair, since nephrons are of an mesenchymal origin, leading to the differentiation of nephrons and collecting ducts. Herrera et al reported that MSC-GFP-positive cells from murine bone marrow, when injected intravenously, homed to the kidneys in mice with glycerol-induced ARF, but not to those in normal mice, differentiated into tubular epithelial cells and promoted the recovery of morphological and functional alterations (10). Lange et al generated a model of ischemia/reperfusion (I/R) ARF in rats and found that infusion of rat MSCs improved recovery of renal function; MSCs were localized in the kidney cortex after injection demonstrated by MRI (11). Kale et al (12) and Morigi et al (13) reported similar findings, and also concluded that it was through differentiation that MSCs contributed to renal injury healing. Wong et al provided evidence that MSCs from human bone marrow had the capacity to differentiate into mesangial cells in vivo after glomerular injury had occurred, but MSCs in uninjured mice were not in the proliferating stage (14).

In contrast, Tögel et al concluded that administered MSCs, which could secrete hepatocyte growth factor (HGF), vascular endothelial growth factor (VEGF), and insulin-like growth factor-I (IGF-I), were able to home to injured microvasculature and inhibit apoptosis. This is an important aspect of MSC-induced renoprotection against ARF and acute 
kidney injury (AKI) through paracrine action $(15,16)$. Moreover, there is controversy on whether the effects of MSCs might be due to fusion between bone marrow cells and injured cells, and not to differentiation $(17,18)$. Other investigators suggest that the effects may be due to the combination of these mechanisms.

Most of the understanding of MSCs and ARF has been acquired from studies on rat or murine MSCs. In the present study, we isolated and expanded rat and human bone marrow-derived MSCs, next administered and evaluated the therapeutic efficacy of MSCs in a rat model of ARF and elucidated a possible mechanism of action for the therapy.

\section{Materials and methods}

Isolation and culture of human MSCs (hMSCs) and rat MSCs ( $r M S C s)$. hMSCs from femurs and tibias of 8- to 12-weekold human female fetuses were obtained as described previously $(2,19)$. Fetuses were obtained from legal abortions performed with vacuum curettage at gestational weeks. Informed consent was obtained from all pregnant women. The harvested cells had a typical spindle-shaped appearance and were positive for CD13, CD29, CD44, CD105, HLA-I, but negative for CD3, CD14, CD15, CD33, CD34, CD38, CD45 and HLA-DR by fluorescence-activated cell sorter (FACS) analysis. The MSC phenotype and purity were further confirmed by the ability to differentiate into osteocytes and adipocytes using respective inductive media (20). rMSCs were isolated from rat bone marrow as described previously for hMSCs.

Rat ARF model. All experimental procedures were conducted in accordance to Chinese legislation on animal protection. Sprague-Dawley (SD) rats were housed in a ventilated (positive airflow) rack and bred and maintained under pathogen-free conditions. Adult female rats weighing 180-220 g were used for all experiments. ARF was induced by intramuscular injection of $50 \%$ glycerol (Shanghai Reagent Co. Ltd., Shanghai, P.R. China) in physiological saline, $8.0 \mathrm{ml} / \mathrm{kg}$, with half of the dose injected into each posterior thigh muscle $(21,22)$. The greatest extent of tubular injury was observed 48-72 $\mathrm{h}$ after glycerol injection.

In vitro co-culture. $\mathrm{rMSCs}$ were co-cultured with normal and glycerol-injured kidney tissues ( $\sim 50 \mathrm{mg}$ in upper chambers) in L-DMEM containing 10\% FBS in trans-well dishes (Corning), separated by a membrane (pore size $0.4 \mu \mathrm{m}$ ) for 3-7 days. The lower chambers were covered with $1 \times 10^{4}$ rMSCs. The kidney tissues were obtained from rats that had been injured with glycerol $48 \mathrm{~h}$ before the co-culture.

MSC administration. hMSCs were administered to ARF rats 48-72 h after injury. As a control, rats were injected intravenously with physiological saline. Blood samples were collected from rats $(n=6)$ to determine serum creatinine before surgery and at 1, 3, 5, 7 and 14 days after glycerol infusion. Creatinine concentrations were determined using a Biochemistry Analyzer (Olympus). Kidney tissues were collected for FISH, PCR, RT-PCR and immunohistochemistry.
Fluorescence in situ hybridization (FISH) analysis. Frozen kidney sections $(4 \mu \mathrm{m})$ were fixed 3 times, $30 \mathrm{~min}$ each, in fixative. They were then rinsed in $2 \mathrm{x}$ SSC for $30 \mathrm{~min}$, airdried, transferred through ice-cold 70, 85 and $100 \%$ ethanol, and air-dried again. Sections were denatured in $70 \%$ formamide for $3 \mathrm{~min}$, and then serial ethanol dehydration was performed again for $3 \mathrm{~min}$ at each concentration. The human $\mathrm{X}$ chromosome probe (Vysis) and dilutions were heated to $72^{\circ} \mathrm{C}$ for $10 \mathrm{~min}$ and placed in a $37^{\circ} \mathrm{C}$ water bath for $5 \mathrm{~min}$ to pre-anneal. Then the sections were incubated with the mixture overnight in a hydrated slide box at $37^{\circ} \mathrm{C}$. The following day, the sections were washed in $0.4 \mathrm{x}$ SSC buffer at $72^{\circ} \mathrm{C}$ and were gently washed in $0.1 \%$ Tritron/2x SSC buffer at room temperature. After washing, slides were counterstained with DAPI (6-diamidino-2-phenylindole). Then cover-slips were placed over the sections and sealed with rubber cement. Fluorescence was analyzed at a chromatosome workstation (Lecia) 45-60 min later.

$P C R$ and $R T-P C R$. The rats were sacrificed two weeks after hMSCs (experimental group) and physiological saline (control group) were infused. DNA from different organs, such as the heart, liver, lungs, brain, and different parts of the kidney, were extracted from the rats and amplified under the following PCR conditions: $94^{\circ} \mathrm{C}$ for $5 \mathrm{~min}, 40$ cycles of PCR $\left(94^{\circ} \mathrm{C}\right.$ for $60 \mathrm{sec}, 64^{\circ} \mathrm{C}$ for $60 \mathrm{sec}, 72^{\circ} \mathrm{C}$ for $120 \mathrm{sec}$ ) and $72^{\circ} \mathrm{C}$ for $10 \mathrm{~min}$ for human $17 \alpha$ satellite DNA.

To detect the specific gene expression of renal tubular epithelial cells, total RNA was isolated using the TRIzol reagent (Invitrogen), and cDNA was synthesized according to the manufacturer's instructions (Toyobo). The cDNA was amplified under the following PCR conditions: $94^{\circ} \mathrm{C}$ for $5 \mathrm{~min}$, 36 cycles of PCR $\left\{94^{\circ} \mathrm{C}\right.$ for $30 \mathrm{sec}, 60^{\circ} \mathrm{C}$ for $30 \mathrm{sec}$ (rat $\mathrm{AQP} 1$, rat PTHR1, rat $\mathrm{CK} 18) / 58^{\circ} \mathrm{C}$ for $30 \mathrm{sec}$ [human $\mathrm{AQP} 1$, human PTHR1, human smooth muscle actin $\left(\alpha\right.$-SMA)], $72^{\circ} \mathrm{C}$ for $30 \mathrm{sec}\}$ and $72^{\circ} \mathrm{C}$ for $10 \mathrm{~min}$. All of the primers were intron-spanning, and are listed in Table I.

Real-time RT-PCR. Real-time RT-PCR was performed to detect the human CK18 gene expression. The reaction mixture contained $1 \mu 1$ of 1:1000 SYBR-Green I, $2.5 \mu 1$ 10x Buffer $\left(\mathrm{Mg}^{2+}\right.$ free), $1.0 \mu \mathrm{l} \mathrm{cDNA}, 0.5 \mu 110 \mu \mathrm{M}$ of each primer, $2.5 \mu 1$ $2 \mathrm{mM} \mathrm{MgCl}_{2}, 2.0 \mu \mathrm{l} 200 \mathrm{nM}$ dNTPs, $1.0 \mu \mathrm{l} \mathrm{BSA}$ and $1 \mathrm{U}$ of Taq DNA polymerase. To compensate for variations in input RNA and the efficiency of reverse transcription, an endogenous 'housekeeping' gene ( $ß$-actin) was also quantified and used to normalize the results. The thermal cycle profile for PCR was as follows: $94^{\circ} \mathrm{C}$ for $5 \mathrm{~min}, 35$ cycles of PCR $\left[94^{\circ} \mathrm{C}\right.$ for $30 \mathrm{sec}, 60^{\circ} \mathrm{C}$ for $30 \mathrm{sec}$ (rat $\mathrm{CK} 18$ ) $/ 56^{\circ} \mathrm{C}$ for $30 \mathrm{sec}$ (ß-actin), $72^{\circ} \mathrm{C}$ for $30 \mathrm{sec}$ ) and $72^{\circ} \mathrm{C}$ for $10 \mathrm{~min}$. The PCR products were size-fractioned by $2 \%$ agarose gel electrophoresis. After PCR, the samples were subjected to a temperature ramp with continuous fluorescence monitoring for melting curve analysis. All samples were run in triplicate, and all reactions were repeated 3 times independently to ensure reproducibility using Rotor-Gene real-time analysis software (Rotor-Gene 2000, CR, Australia).

Histology and immunohistochemistry. Formalin-fixed and 5- $\mu \mathrm{m}$ kidney paraffin-embedded sections were routinely stained with 

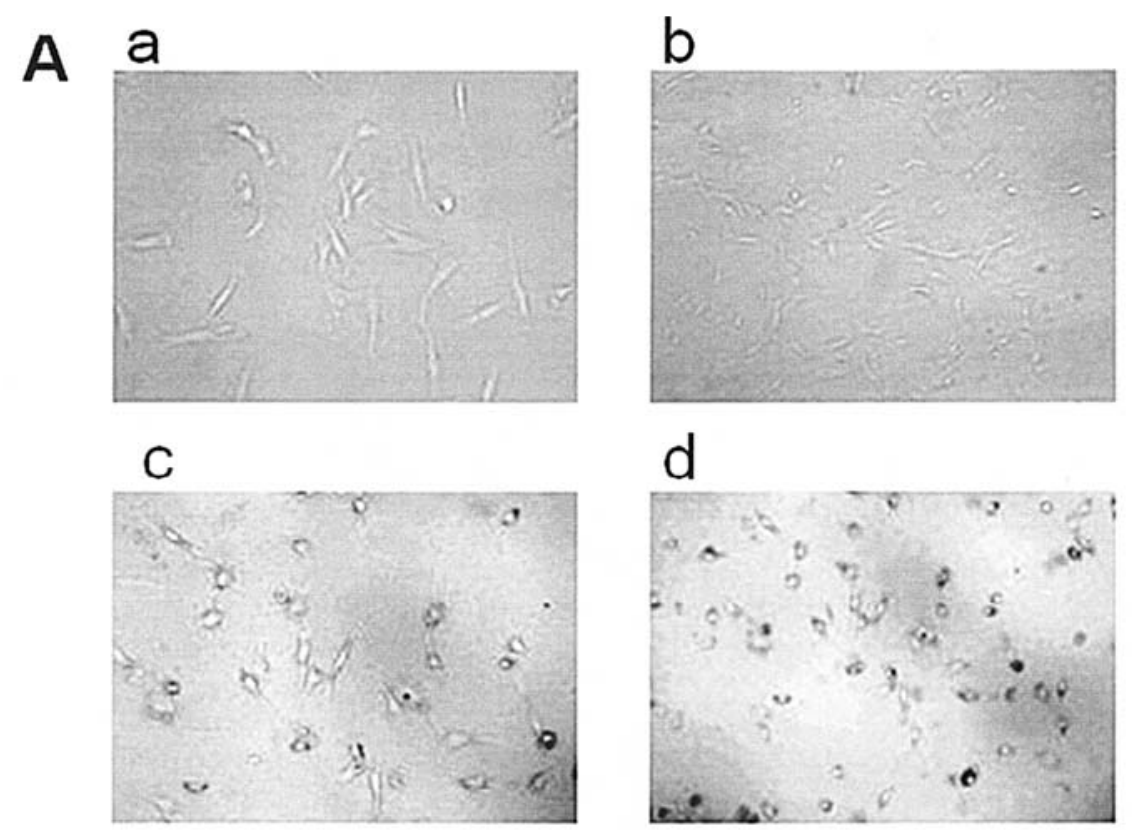

B
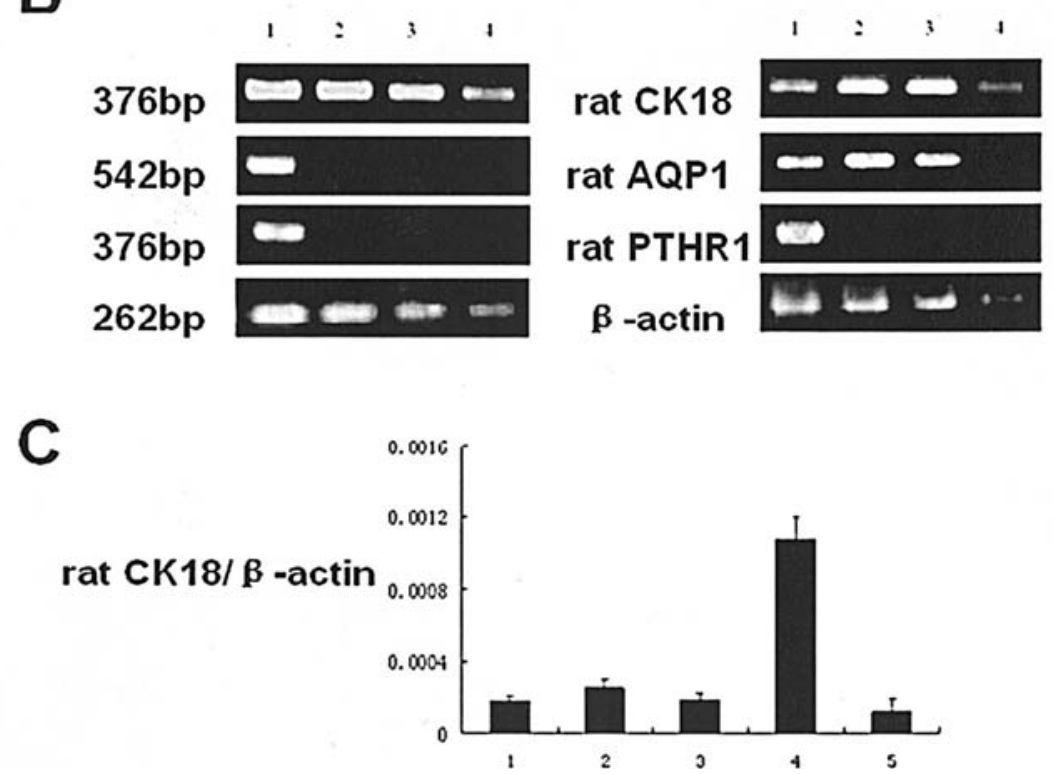

Figure 1. rMSC differentiation induced by injured kidney tissues in vitro. (A) Appearance of rMSCs co-cultured with rat kidney tissues. Morphological changes of rMSCs co-cultured with normal kidney tissues after 3 (a, x200) and 7 (b, x100) days. Morphological changes of rMSCs co-cultured with injured kidney tissues after 3 (c, x200) and 7 (d, x100) days. (B) RT-PCR for the expression of rat AQP1, PTHR1, CK18 and B-actin genes. (Left) RT-PCR of rMSCs co-cultured with normal kidney tissues. Lane 1, normal kidney tissues; lane 2 and 3, rMSCs co-cultured with normal kidney tissues for 3 and 7 days; lane 4, rMSCs. (Right) RT-PCR of rMSC co-cultured with injured kidney tissues. Lane 1, injured kidney tissues; lane 2 and 3, rMSCs co-cultured with injured kidney tissues for 3 and 7 days; lane 4, rMSCs. (C) Real-time quantitative PCR for rat CK18 gene. Lane 1 and 2, rMSCs co-cultured with normal kidney tissues for 3 and 7 days; lane 3 and 4, rMSCs co-cultured with injured kidney tissues for 3 and 7 days; lane 5, rMSCs (repeated 3 times).

hematoxylin and eosin (H\&E) in order to observe the pathological changes between animals in the experimental group and the control group. Kidney sections were adsorbed on polylysine-coated glass slides, air-dried, deparaffinized, and then placed in a water bath. The sections were treated with heating for antigen retrieval. For peroxidase-linked immunostaining, endogenous peroxidase was removed by $3 \%$ hydrogen peroxide $\left(\mathrm{H}_{2} \mathrm{O}_{2}\right)$ for $5 \mathrm{~min}$. Non-specificities were blocked by $5 \%$ bovine serum albumin. The kidney specimens were incubated with antibodies against human $\alpha$-SMA (Chemicon), human thymus cell antigen1 (Thy-1, eBioscience) and CK18 (Boster) in appropriate concentrations. An antibody against human and rat proliferative nuclear cell antigen (PCNA, Boster) was employed according to the manufacturer's instructions for the staining procedure.

Statistics. SPSS software was used to analyze the data by the Student's t-test. $\mathrm{P}<0.05$ was considered statistically siginificant.

\section{Results}

rMSC differentiation induced by injured kidney tissues in vitro. There were no visible morphological changes after 3 and 7 days in rMSCs co-cultured with normal kidney tissues 
Table I. Primer sequences of target genes.

\begin{tabular}{llc}
\hline Genes & \multicolumn{1}{c}{ Primer sequence (5'-3') } & Amplification size (bp) \\
\hline Human $17 \alpha$ & For: ACACTCTTTTGCAGGATCTA & 1171 \\
& Rev: AGCAATGTGAAACTCTGGGA & \\
Human $\alpha$-SMA & For: CTGACTGAGCGTGGCTATTC & 452 \\
& Rev: CCACCGATCCAGACAGAGTA & \\
Human AQP1 & For: TGCTATGCGTGCTGGCTACT & 283 \\
Human PTHR1 & Rev: ACCTTCACGCGGTCTGTGAG & \\
& For: CTCAAGGAGGTCCTGCAGAG & 475 \\
Rat CK18 & Rev: CCAGGATGAGCACAGCTACG & \\
Rat AQP1 & For: GGAGGCATCCAGAACGAGAA \\
& Rev: CCAGCTGCAGTCGTGTGATA & 376 \\
Rat PTHR1 & For: CCAGCGAAATCAAGAAGAAG & \\
Rev: CCAGCGAAATCAAGAAGAAG & 542 \\
Rat/human $\beta$-actin & For: CTCAGGGACATTGTGGCAGAT & 376 \\
& Rev: CTTGGGAACCGCCATAGTGA & \\
\hline
\end{tabular}

A

$1171 \mathrm{bp}$

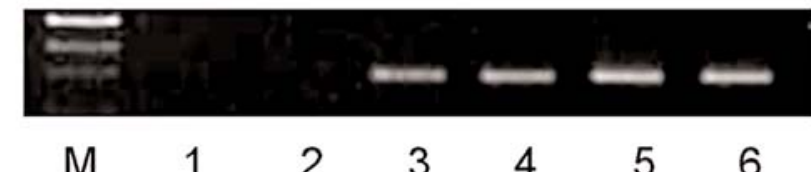

human $17 a$

B

$\begin{array}{lllllll}M & 1 & 2 & 3 & 4 & 5 & 6\end{array}$

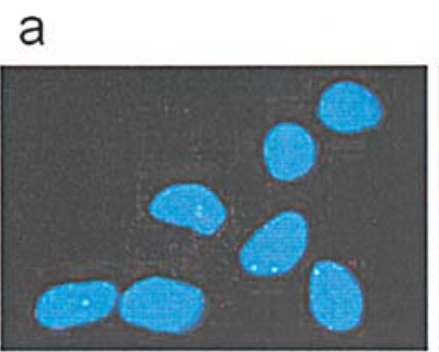

b

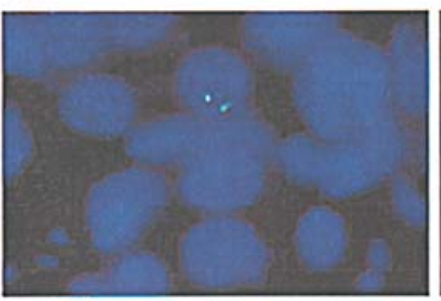

C

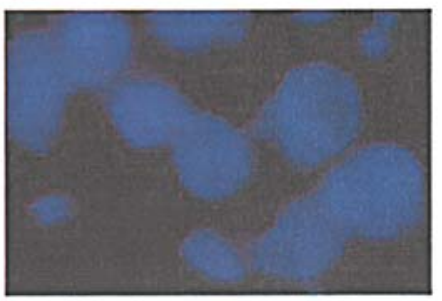

Figure 2. MSCs migrated and were located in SD rats with ARF. (A) Identification of infused hMSCs in tissues of SD rats with ARF. PCR for human $17 \alpha$ satellite DNA sequence in different kidney tissues of rats with ARF. Lane 1, blank; lane 2, kidney tissues of the control group. Lanes 3-6, kidney tissues of the experimental group: lane 3, kidney tissues; lane 4, renal cortex; lane 5, renal medulla; lane 6, renal pelvis. (B) Human X chromosome FISH analysis of kidney section from the rat: hMSCs (a, positive control, $\mathrm{x} 400$ ); frozen section of rat kidney tissues from the hMSC-infused group (b, experimental group, $\mathrm{x} 400$ ); frozen section of rat kidney tissues from the saline-treated group (c, control group, $\mathrm{x} 400)$.

(Fig. 1A, a and b). In contrast to this, the damaged kidney tissues induced rMSCs to become rounded by day 3 of culture (Fig. 1A, c) and to present more rounded or elliptical cells on day 7 (Fig. 1A, d). The cells showed the morphological characteristics of renal tubular epithelial-like cells.

RT-PCR analysis revealed that rMSCs did not express AQP1 and PTHR1. However, the cells co-cultured with damaged kidney tissues highly expressed rat AQP1, but not PTHR1 (Fig. 1B, right). The MSCs co-cultured with normal kidney tissues also did not express rat AQP1 or PTHR1
(Fig. 1B, left). Expression of the epithelial marker CK18 was observed for co-cultured rMSCs, regardless of whether the kidney was normal or damaged (Fig. 1B). Real-time PCR analysis showed that rMSCs induced by injured kidney tissues expressed rat CK18 more highly, compared with rMSCs. However, there were no significant differences between cells induced by normal kidney tissues and rMSCs (Fig. 1C).

Exogenous MSCs preferentially accumulate in injured kidneys in vivo. When hMSCs were infused into rats, the 
A

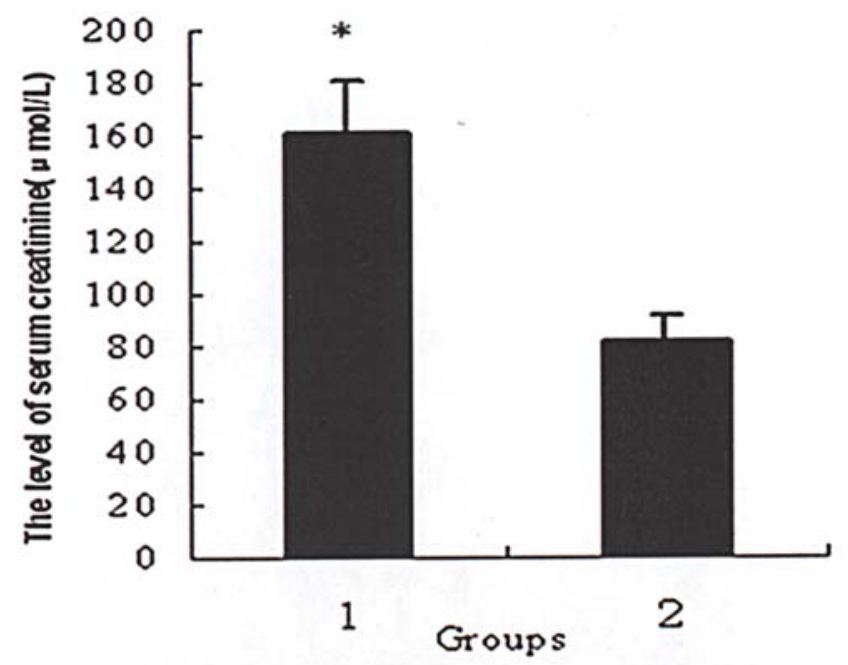

B

b

c

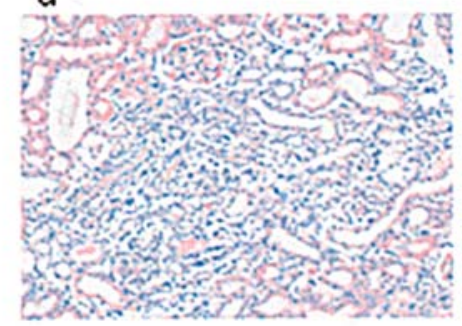

b
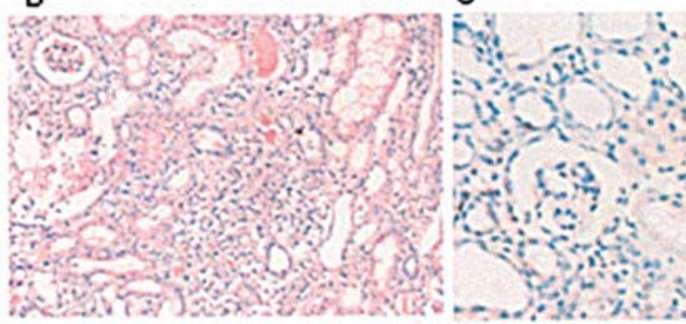

d

e

f

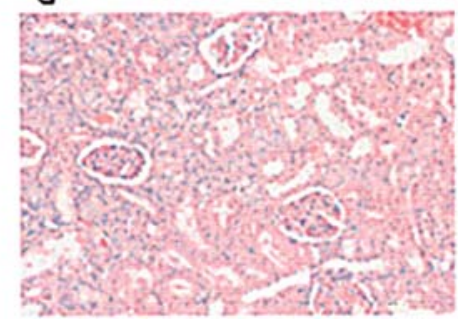

e

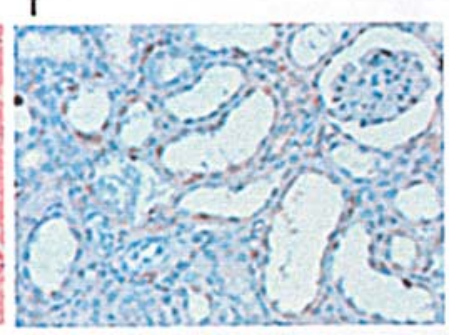

Figure 3. Infusion of hMSCs leads to faster recovery from kidney injury. (A) Comparison of the level of serum creatinine on day 5 after infusion. Group 1, control (saline-treated); Group 2, experimental (hMSC-treated); $\mathrm{P} \leq 0.05$ (repeated 3 times). (B) Renal histological changes of the experimental and control groups. H\&E staining for kidney tissues in the control group (a, x200; b, x400) and in the experimental group (d, x200; e, x400). Immunohistochemical staining for PCNA in kidney tissues of the control group $(c, x 400)$ and experimental group (f, $x 400)$.

human $17 \alpha$ satellite DNA sequence was detected from different parts of the rat kidney. There was no detectable human DNA in rats treated with saline (control group) (Fig. 2A). Green fluorescence from the $\mathrm{X}$ chromosome probe was observed by fluorescence microscopy in the kidneys of MSC-infused animals two weeks after infusion of the cells, but was not found in the control group (Fig. 2B).

hMSCs lead to faster recovery from kidney injury after infusion. After glycerol injection, we observed marked tubular epithelial injury, and serum creatinine levels were elevated. On the fifth day after MSC infusion, the serum creatinine concentration was significantly lower in MSC-treated rats compared with control groups $(\mathrm{P}<0.05)$ (Fig. 3A). This was confirmed by pathological examination of the kidney sections, which indicated that the experimental group was recovering more rapidly than the control group. The degree of microaggregate-like degeneration and necrosis of renal tubular epithelial cells and the congestion of renal glomeruli were lower in hMSC-treated rats (experimental group) (Fig. 3B, d and e) than in the control group (Fig. 3B, a and b). Early tubular regeneration was demonstrated by PCNA immunohistochemistry. There were many more nuclei stained for PCNA among the renal tubular epithelial cells in the experimental group (Fig. 3B, f) than in control group (Fig. 3B, c).

Human renal tubular epithelial-like cells generate from hMSCs in vivo. To evaluate whether hMSC may differentiate into epithelial cells, we observed human gene expression in the kidney ARF model. Before injection, the MSCs did not express any of these epithelial markers. RT-PCR revealed the presence of specific fragments of human AQP1 and human PTHR1 in human and experimental group kidney tissues. No amplification was shown in kidney tissue of the control group. Human $\alpha$-SMA mRNA was detectable in different parts of the kidney from rats which were infused with hMSCs (Fig. 4A).

Compared with the control group (Fig. 4B, b), the kidney sections of hMSC-infused rats treated with the specific antibody against human $\alpha$-SMA, showed that there was a number of cells with light brown coloration (Fig. 4B, c and d). 
A

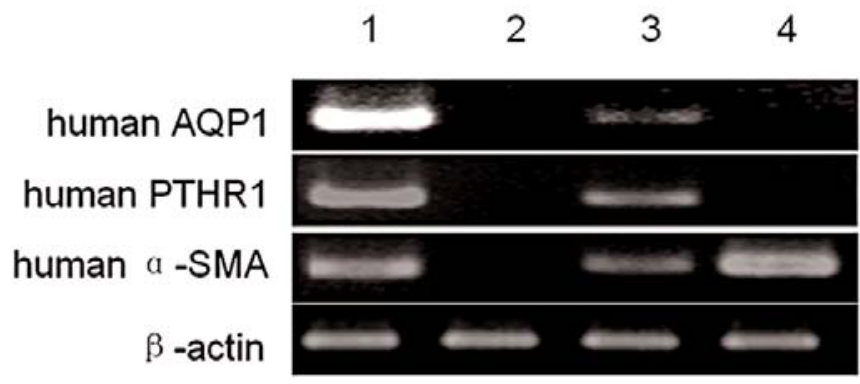

B
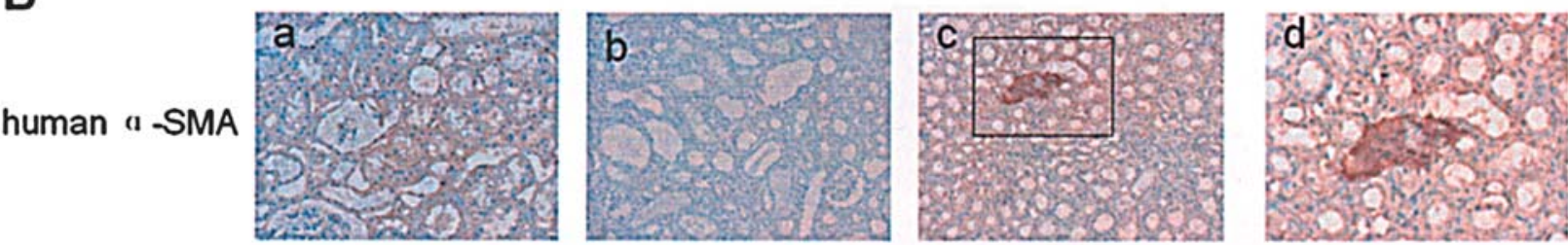

human Thy-1
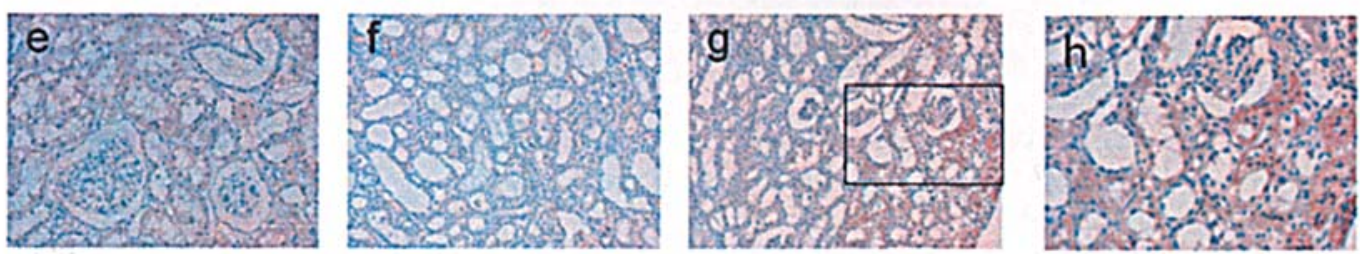

human CK-18
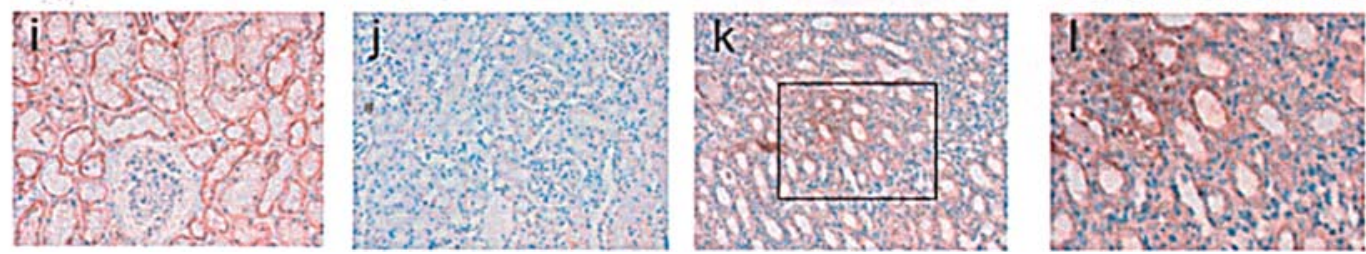

Figure 4. Human renal tubular epithelial-like cells generated in vivo from infused hMSCs. (A) RT-PCR analysis of human kidney-specific gene expression in rats with ARF. Lane 1, human kidney tissues; lane 2, rat kidney tissues of the control group; lane 3, rat kidney tissues of the experimental group; lane 4, hMSCs. (B) Immunohistochemical staining for human $\alpha$-SMA, human Thy-1 and human CK18 in rats with ARF. Staining for human $\alpha$-SMA in human kidney tissues (a, x200); rat kidney tissues of the control group (b, x200); rat kidney tissues of the experimental group (c, x200; d, x400). Staining for human Thy-1 in human kidney tissues (e, x200); rat kidney tissues of the control group (f, x200); rat tissues of the experimental group (g, x200; h, x400). Staining for human CK18 in human kidney tissues (i, x200); rat kidney tissues of the control group ( $\mathrm{x} 200$ ); rat kidney tissues of the experimental group ( $\mathrm{k}$, x200; 1 , x400). $\mathrm{d}$, $\mathrm{h}$ and 1 , magnified images of corresponding squared areas of $\mathrm{c}, \mathrm{g}$ and $\mathrm{k}$, respectively.

Fig. 4B also showed that some cells were positive for human Thy-1 ( $\mathrm{g}$ and $\mathrm{h}$ ) and human CK18 ( $\mathrm{k}$ and $\mathrm{l}$ ) in the experimental group, but negative in the control group ( $f$ and $\mathrm{j}$ ). Most positive cells were located in the renal tubular structures.

\section{Discussion}

In recent years, stem cell therapy has become a new focal point in regeneration medicine. Although controversial, many studies suggest that MSCs may contribute to the recovery of acute renal injury (23-26). Several lines of evidence indicate that exogenously administered MSCs do modulate the kidney repair and regenerative response. Administration of MSCs represents a promising strategy that has many benefits over the use of conventional stem cells, but many obstacles must be overcome before the technology can be implemented for therapy. These problems include the selection of proper animal models for preclinical studies, determination of the number of cells to be used, the method of delivery or infusion of the cells, and evidence that the infusion or administration of the cells can be safe and effective. All of the latter are still under investigation, but progress is being made.
ARF associated with nephrotoxic injury is most often the consequence of acute tubular necrosis. In the present study, we successfully generated a rat model of ARF using glycerol, which caused dysfunction and loss of tubular epithelial cells due to toxic challenge (22). When the kidneys were damaged by glycerol, renal tubular cells degenerated and underwent necrosis. Vascular endothelial cells were injured and released IL-6, TNF $\alpha$, IL-1ß, ICAM-1 and VCAM-1, which contributed to the renal damage (27). Within 1-2 h, the rats excreted bloody urine. Creatinine and urea nitrogen in the serum of glyceroltreated rats were higher than in normal rats. Creatinine and urea nitrogen in serum began to increase within $24 \mathrm{~h}$, and the serum concentration peaked at $72 \mathrm{~h}$. Both kidneys in all animals were tumescent, tubular epithelial cells appeared disorganized and necrotic, and the glomerulus appeared to be congested when examined in sacrificed rats.

Co-cultured with kidney tissues in vitro, rMSCs grew slowly in the lower chamber of trans-well dishes exposed to normal rat kidney tissues. However, the shape of rMSC become rounded or elliptical (epitheliod), and the cells highly expressed CK18 and AQP1 when co-cultured with kidney tissues of injured rats with ARF. The results suggest that the 
injured kidney tissues induced rMSCs to differentiate into renal tubular epithelial-like cells.

The mechanisms by which MSCs promote kidney repair remain unclear, but an important aspect of the therapeutic effects of MSC is their apparent ability to home to injured organs. Recent studies have demonstrated the signals that regulate MSC homing. It has been suggested that MSCs have the ability for chemoattraction to stromal-derived factor-1 (SDF-1) gradient within the damaged tissue (28). Chemokine SDF-1 binds to its receptor CXCR4, which is expressed in the distal tubule, and is up-regulated after renal injury (29). CXCR4 is expressed in MSCs. Its expression is up-regulated by hypoxia, and the SDF-1/CXCR4 pair is known to regulate hematopoietic stem cell migration. Furthermore, hypoxic preincubation of MSCs appears to increase engraftment in vivo (30). Studies have reported that in vivo, MSCs injected into mice with ARF migrated to the injured kidney, where the receptor for $\mathrm{CD} 44$, hyaluronic acid, is up-regulated in the kidney after injury. A recently described candidate for regulation of MSC homing is CD44, which is expressed on MSCs and is required for renal localization of injected MSCs after glycerol-induced renal injury. Renal localization of the MSCs was blocked by pre-incubation with the CD44 blocking antibody or by soluble hyaluronic acid. Stem cells derived from CD44 knockout mice did not localize to the injured kidney and did not accelerate morphological or functional recovery. It was suggested that CD44 and hyaluronic acid recruit exogenous MSCs to injured renal tissue and enhance renal regeneration (31).

In support of MSCs being attracted to damaged tissues, we observed that when hMSCs were infused into the rats, a human satellite DNA sequence was amplified from the rat hearts, livers, and different parts of the kidneys (results partly not shown). FISH analysis indicated that human cells preferentially localized around the injured tubular cells. Our findings indicate that hMSCs can accumulate in injured kidneys in rats and have provided the base of the biological function of MSCs in vivo.

The recruitment of MSCs within the injured kidneys accelerated functional and morphological recovery. Using hMSC transplantation in the rats with ARF, demonstrating the activity of the MSCs, the levels of serum creatinine were significantly decreased in the experimental group compared with the control group. Moreover, kidneys recovered faster in the experimental group, and the MSCs led to repair of the renal injury as well as improvement in renal function. hMSCs were responsible for improving the kidney function of the rats.

As the glycerol injection caused kidney dysfunction and loss of tubular epithelial cells, we wanted to determine whether the MSCs were being induced to form new renal tubular epithelial-like cells in the animal model. To examine whether this mechanism of action was responsible for the improvement in renal function following hMSC infusion, we selected several human kidney-specific genes to be amplified in the different parts of the kidney tissues. We found that the expression of human AQP1, PTHR1 and $\alpha$-SMA were detectable by RTPCR in the kidney tissues. Moreover, immunohistochemistry showed that human $\alpha$-SMA, Thy-1, and CK18 were positive in the kidney tissues of the experimental group. These findings indicate that human MSCs can differentiate into renal tubular epithelial-like cells in the damaged kidney in vivo.

All of these findings suggest that exogenous MSCs can home to the injured kidneys and that they play a therapeutic role in improving renal function. This indicates that MSCs may represent a new treatment option for ARF, and differentiation of MSC into renal tubular epithelial-like cells is responsible for these effects.

Different clinical studies evaluating MSCs have had promising results and no apparent toxicities. However, safety issues surrounding the use of MSCs for therapy have not yet been fully explored. We indicated that the MSCs may produce rare tumors (32). In-depth toxicity and efficacy studies need to be accomplished. Several important points still need to be addressed, including a more thorough investigation into the various ways in which MSCs can be used therapeutically, the transition from the bench to the clinic, and the concern of any unwanted effects. The following few years are likely to yield significant discoveries about MSCs and their potential applications.

\section{Acknowledgements}

This work was supported by the National Natural Science Foundation of China, grant no. 30471983, the Natural Science Foundation of the Jiangsu Province, grant nos. BK2007092 and BK2007705, the Natural Science Foundation of the Ministry of Public Health of China, grant no. WKJ2005-2-024, the Foundation of Zhenjiang Key Institute of Clinical Laboratory Medicine, grant nos. SH2006066 and SH2006070, the Jiangsu Province's Outstanding Medical Academic Leader Program, grant no. LJ200614 and the Scientific Research Foundation of Jiangsu University, grant no. 07JDG056. We thank the Innovation Center for Medical Graduate Student Studies of Jiangsu Province for helpful and critical reading of the manuscript.

\section{References}

1. Tsai RY, Kittappa R and McKay RD: Plasticity, niches and the use of stem cells. Dev Cell 2: 707-712, 2002.

2. Xu W, Zhang X, Qian H, Zhu W, Sun X, Hu J, Zhou H and Chen Y: Mesenchymal stem cells from adult human bone marrow differentiated into cardiocytes in vitro. Exp Biol Med 229: 623-631, 2004

3. Zhu W, Xu W, Sun X and Lian F: An experimental study on osteogenic differentiation of bone marrow mesenchymal stem cells in vivo. J Biol Eng Res 22: 41-43, 2003.

4. Nöth U, Rackwitz L, Heymer A, Weber M, Baumann B, Steinert A, Schütze N, Jakob F and Eulert J: Chondrogenic differentiation of human mesenchymal stem cells in collagen type I hydrogels. J Biomed Mater Res A 83: 626-635, 2007.

5. Sun X, Xu W, Yao K, Hu J, Qian H and Zhang X: Preliminary research on induction of fetal bone marrow mesenchymal stem cells differentiation into neural cells in vitro. Chin J Biol Eng 23: 40-43, 2004.

6. Xiang Y, Zheng Q, Jia B, Huang G, Xie C, Pan J and Wang J: Ex vivo expansion, adipogenesis and neurogenesis of cryopreserved human bone marrow mesenchymal stem cells. Cell Biol Int 31: 444-450, 2007.

7. Pittenger MF and Martin BJ: Mesenchymal stem cells and their potential as cardiac therapeutics. Circ Res 95: 9-20, 2004.

8. Natsu K, Ochi M, Mochizuki Y, Hachisuka H, Yanada S and Yasunaga Y: Allogeneic bone marrow-derived mesenchymal stromal cells promote the regeneration of injured skeletal muscle without differentiation into myofibers. Tissue Eng 10: 1093-1112, 2004. 
9. Olle L, Zaal K and Alberto MS: Stem cell therapy for human neurodegenerative disorders how to make it work. Neurodegeneration 7: 42-50, 2004.

10. Herrera MB, Bussolati B, Bruno S, Fonsato V, Romanazzi GM and Camussi G: Mesenchymal stem cells contribute to the renal repair of acute tubular epithelial injury. Int J Mol Med 14: 1035-1041, 2004.

11. Lange C, Tögel F, Ittrich H, Clayton F, Nolte-Ernsting C, Zander AR and Westenfelder C: Administered mesenchymal stem cells enhance recovery from ischemia/reperfusion-induced acute renal failure in rats. Kidney Int 68: 1613-1617, 2005.

12. Kale S, Karihaloo A, Clark PR, Kashgarian M, Krause DS and Cantley LG: Bone marrow stem cells contribute to repair of the ischemically injured renal tubule. J Clin Invest 112: 42-49, 2003.

13. Morigi M, Imberti B, Zoja C, Corna D, Tomasoni S, Abbate M, Rottoli D, Angioletti S, Benigni A, Perico N, Alison M and Remuzzi G: Mesenchymal stem cells are renotropic, helping to repair the kidney and improve function in acute renal failure. J Am Soc Nephrol 115: 1794-1804, 2004.

14. Wong C, Cheong S, Mok P and Leong C: Differentiation of human mesenchymal stem cells into mesangial cells in postglomerular injury murine model. Pathology 40: 52-57, 2008.

15. Tögel F, Hu Z, Weiss K, Isaac J, Lange C and Westenfelder C: Administered mesenchymal stem cells protect against ischemic acute renal failure through differentiation-independent mechanisms. Am J Physiol Renal Physiol 289: F31-F42, 2005.

16. Tögel F, Weiss K, Yang Y, Hu Z, Zhang P and Westenfelder C: Vasculotropic, paracrine actions of infused mesenchymal stem cells are important to the recovery from acute kidney injury. Am J Physiol Renal Physiol 292: F1626-F1635, 2007.

17. Camargo FD, Finegold M and Goodell MA: Hematopoietic myelomonocytic cells are the major source of hepatocyte fusion partners. J Clin Invest 113: 1266-1270, 2004

18. Willenbring H, Bailey AS, Foster M, Akkari Y, Dorrell C, Olson S, Finegold M, Fleming WH and Grompe M: Myelomonocytic cells are sufficient for therapeutic cell fusion in liver. Nat Med 10: 744-748, 2004

19. Qian H, Xu W, Zhang X, Sun X, Zhu W and Hu J: Basic biological characteristics, isolation and purification of mesenchymal stem cells derived from embryonic bone marrow. Acta Anatomica Sinica 35: 440-442, 2004.

20. Qiao C, Xu W, Zhu W, Hu J, Qian H, Yin Q, Jiang R, Yan Y, Mao F, Yang H, Wang $\mathrm{X}$ and Chen $\mathrm{Y}$ : Human mesenchymal stem cells isolated from the umbilical cord. Cell Biol Int 32: 8-15, 2008 .
21. Zager RA, Burkhart KM, Conrad DS and Gmur DJ: Iron, heme oxygenase, and glutathione: effects on myohemoglobinuric proximal tubular injury. Kidney Int 48: 1624-1634, 1995.

22. Nath KA, Balla G, Vercellotti GM, Balla J, Jacob HS, Levitt MD and Rosenberg ME: Induction of heme oxygenase is a rapid, protective response in rhabdomyolysis in the rat. J Clin Invest 90: 267-270, 1992.

23. Vigneau C, Zheng F, Polgar K, Wilson PD and Striker: G Stem cells and kidney injury. Curr Opin Nephrol Hypertens 15: 238-244, 2006.

24. Ricardo SD and Deane JA: Adult stem cells in renal injury and repair. Nephrology 10: 276-282, 2005.

25. Brodie JC and Humes HD: Stem cell approaches for the treatment of renal failure. Pharmacol Rev 57: 299-313, 2005.

26. Haller H: Regenerative therapy in nephrology: Repair or construction? Internist 48: 813-818, 2007.

27. Bellomo R, Bonventre J, Macias W and Pinsky M: Management of early acute renal failure: focus on post-injury prevention. Curr Opin Crit Care 11: 542-547, 2005.

28. Wynn RF, Hart CA, Corradi-Perini C, O'Neill L, Evans CA, Wraith JE, Fairbairn LJ and Bellantuono I: A small proportion of mesenchymal stem cells strongly expresses functionally active CXCR4 receptor capable of promoting migration to bone marrow. Blood 104: 2643-2645, 2004.

29. Tögel F, Isaac J, Hu Z, Weiss K and Westenfelder C: Renal SDF-1 signals mobilization and homing of CXCR4-positive cells to the kidney after ischemic injury. Kidney Int 67: 1772-1784, 2005.

30. Hung SC, Pochampally RR, Hsu SC, Sanchez C, Chen SC, Spees J and Prockop DJ: Short-term exposure of multipotent stromal cells to low oxygen increases their expression of CX3CR1 and CXCR4 and their engraftment in vivo. PLoS One 2, e416, 2007.

31. Herrera MB, Bussolati B, Bruno S, Morando L, MaurielloRomanazzi G, Sanavio F, Stamenkovic I, Biancone L and Camussi G: Exogenous mesenchymal stem cells localize to the kidney by means of CD44 following acute tubular injury. Kidney Int 72: 430-441, 2007.

32. Xu W, Qian H, Zhu W, Chen Y, Shao Q, Sun X, Hu J, Han C and Zhang X: A novel tumor cell line cloned from mutated human embryonic bone marrow mesenchymal stem cells. Oncol Rep 12: 501-508, 2004. 